\title{
Detection and Genetic Analysis of Imported Malaria in Egypt
}

\author{
Hossam Eldin A. Romeh ${ }^{* 1}$ MSc, Khairy A. Hassan ${ }^{2}$ MD, Mohamed A. Abd El Rehem ${ }^{1}$ MD, Anwar Hussainy \\ Abo-hashim ${ }^{2}$ MD, Ayman A. El-Badry ${ }^{3,4}$ MD
}

\begin{abstract}
*Corresponding Author
Hossam Eldin A. Romeh

Hossameldine678@yahoo.com

Received for publication January 22,

2020; Accepted May 8, 2020.

Published online July, 31, 2020

Copyright 2020 The Authors published by Al-Azhar University, Faculty of Medicine, Cairo, Egypt. All rights reserved. This an openaccess article distributed under the legal terms, where it is permissible to download and share the work provided it is properly cited. The work cannot be changed in any way or used commercially.
\end{abstract}

doi:10.21608/aimj.2020.22391.1075

${ }^{1}$ Department of Medical Parasitology, Al-Azhar University, Assiut, Egypt.

${ }^{2}$ Department of Medical Parasitology, Al-Azhar University, Cairo, Egypt.

${ }^{3}$ Department of Medical Parasitology, Kasar Al-Ainy Faculty of Medicine, Cairo University, Cairo, Egypt.

${ }^{4}$ Department of Microbiology, Medical Parasitology Section, College of Medicine, Imam Abdulrahman Bin Faisal University,

Dammam, Saudi Arabia.

\section{ABSTRACT}

Background: Microscopy is considered the gold standard test for diagnosis of malaria but it needs experienced microscopists. Serological tests and nPCR is providing efficient diagnostic tests and are applied for malaria diagnosis and research.

Aim of The Work: This work aimed to the detection and genetic analysis of imported malaria in Egypt.

Patients and Methods: This study was a cross-sectional one where a total of 750 blood samples were collected from different laboratories in Cairo, Egypt from persons who travel to African endemic areas, and came to Egypt within the previous 8 weeks; during the period from August 2017 to August 2018. All samples were examined microscopically, immunologically by rapid diagnostic tests (RDT) and 21 positive cases were examined by $\mathrm{nPCR}$ as a confirmatory test, and for the detection of parasitic genotypes.

Results: Plasmodium species were identified microscopically in $27(3.6 \%)$ out of 750 individuals, 13 of them were diagnosed as $P$. falciparum, 7 were P.vivax, one was P.ovale and 6 were mixed infections with P.falciparum and P.vivax. Confirmed results by nPCR revealed that 12 cases were $P$.falciparum; 5 cases were $P$. Vaivax and 4 were mixed infections. The results of nPCR were identical to the microscopic results.

Conclusion: The major two species of imported malaria to Egypt were P.vivax and P.falciparum. Detection of malaria species microscopically is stilled the gold standard method. Nested PCR tests are highly accurate, sensitive, specific, and able to differentiate between malaria species

Disclosure: The authors have no financial interest to declare in relation to the content of this article. The Article Processing Charge was paid for by the authors.

Authorship: All authors have a substantial contribution to the article

\section{INTRODUCTION}

Malaria is a disease that affects about 3.4 million persons $^{1}$ of which 2.57 million and 2.5 million are at risk for P.falciparum and P.vivax respectively while P.ovale and P.malariae have a small percentage. ${ }^{2}$ WHO recorded in the world Malaria Report 2012 that 1.2 million people died due to malaria infection ${ }^{3}$. In Africa, malaria is considered the second cause of death among transmitting diseases after AIDS ${ }^{4}$.

WHO considers malaria as a treatable, controllable, and preventable disease ${ }^{5}$. So, a lot of malaria control interventions were applied including indoor residual spray (IRS) ${ }^{\mathbf{6}}$. Artemisinin combined treatment (ACT) was used as the 1 st-line of treatment ${ }^{7}$.

Examination of blood smears (stained by Giemsa) microscopically is considered the standard method for malaria diagnosis ${ }^{\mathbf{8}}$ where parasitic stages can be detected by microscopists. Detection of malarial antigens by RDTs as well as PCR are considered other new important methods for the diagnosis of malaria ${ }^{9}$.

Screening protocol for malaria species has 2 steps: First, a rapid real-time PCR to detect malaria parasites by targeting their gene including ssRNA genes. The second is conventional PCR including nested-PCR (nt-PCR) assays (for +ve samples) ${ }^{\mathbf{1 0}}$. 
Screening of malaria is necessary to detect hot areas of malaria infection where control measures are not effective ${ }^{11}$. So, the present work aimed to screen imported malaria in Egypt.

\section{PATIENTS AND METHODS}

This study is a cross-sectional one. It was performed to detect the prevailing malaria species in seven hundred and fifteen blood samples. The blood samples were collected from different medical laboratories in Cairo from travelers to endemic African areas either Egyptians or foreigners coming to Egypt within the previous eight weeks, in the period from August 2017 to August 2018. Malaria diagnosis was determined according to clinical manifestations, travel history, and the positive results of microscopic examination as well as RDTs [Abon Biopharm (Hangzhou) Co., Ltd., China]. Thin and thick blood films were prepared from all blood samples then RDT was performed to all blood samples, the rest of blood samples were collected in dry clean sterile tubes which contain EDTA, then stored at $2-8 \mathrm{C}$ for up to 3 days or at $-20^{\circ} \mathrm{C}$ to store it for a longer duration for molecular studies (PCR and nPCR).

Parasitological Examination: Thin and thick blood films were prepared and stained by $10 \%$ Giemsastain $^{12}$, then examined microscopically by experts. Immunological method: RDT interpretation: $\mathrm{C}$ band development indicates test validity. In case of presence of $\mathrm{C}$ band only indicate -ve result. The presence of pf band (with $\mathrm{C}$ band) indicates +ve result for $P$. falciparum (Fig.1).

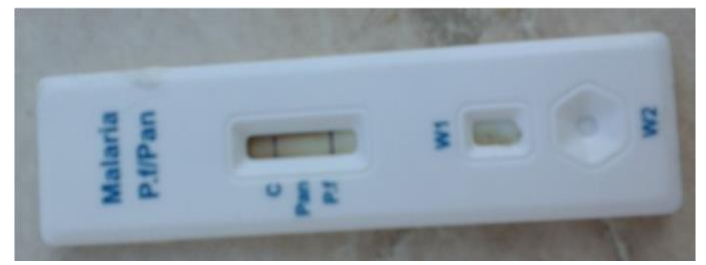

Figure (1): P. falciparum + ve RDT

The presence of a pan band (with $\mathrm{C}$ band) indicates +ve results for P.vivax, P.ovale, or P. malariae. (Fig. 2).

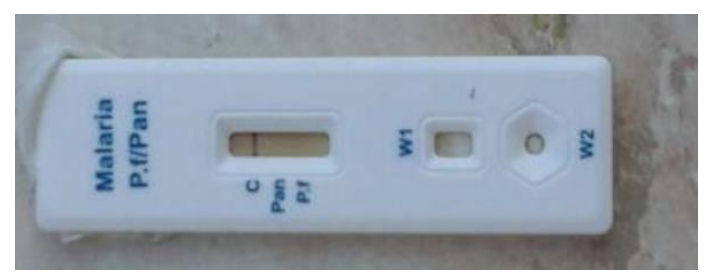

Figure (2): Species - ve RDT

Molecular Studies: All microscopically positive blood samples for Plasmodium were subjected for nested-PCR (nPCR) analysis. The molecular assay was done in 3 main steps:

i.Extraction of genomic DNA from blood: We use (the Monarch PCR \& DNA Cleanup Kit) to extract Genomic DNA from all dried blood samples.

ii. Amplification of extracted genomic DNA using nPCR: Extracted genomic DNA from each blood sample was used for PCR amplification, using
Monarch PCR \& DNA Cleanup Kit according to the manufacturer's instructions.

Using the primers designed based on the sequence of SSU rRNA of Plasmodium ${ }^{13}$. The sense and antisense primers of plasmodium species which were (rPLU5) 5'CCT GTT GTT GCC TTA AAC TTC-3` and(rPLU6) 5-TTA AAA TTG TTG CAG TTA AAA CG-3', respectively were used in the first PCR. PCR product size $1100 \mathrm{bp}$ was recovered in positive samples. PCR products from Plasmodium genomic DNA were amplified using the rPLU1 and rPLU5 primers for detection of Plasmodium species, while further amplified in nested (second) PCR 4 reactions used the sense and antisense primers of (i) P. falciparum [the sense primer (rFAL1) 5-TTA AAC TGG TTT GGG AAA ACC AAA TAT ATT-3 3 and antisense primer (rFAL2) 5-ACA CAA TGA ACT CAA TCA TGA CTA CCC GTC-3`] with PCR product size 205 bp, (ii) P.vivex [(PV18SF ) 5-GAA TTT TCT CTT CGG AGT TTA TTC-3` and (PV18SR) 5'-GTA GAA AAG GGA AAG GGA AAC TGT TA-3` ]with PCR product size 419 bp, (iii) P. malariae [(PM18SF) 5'-GAG ACA TTC ATA TAT ATG AGT GTT TCT-3` and (PM18SR)5 GGG AAA AGA ACG TTT TTA TTA AAA AAA AC-3`] with PCR product size 423 bp, (iv) $P$. ovale [(PO18SF) 5-GAA AAT TCC TTT TGG AAA TTT CTT AG-3` and (PO18SR) 5-GGG AAA AGG ACA CTA TAA TGT ATC-3`] with PCR product size 410 bp 14 .

Three microliters of the DNA template were used for PCR amplification in the reaction mixture of the master mix and 50 pmol of each primer. PCR cycling condition for $1^{\text {st }}$ PCR was as follows: denaturation at $94^{\circ} \mathrm{C}$ for $4 \mathrm{~min}$, followed by 35 cycles of $94^{\circ} \mathrm{C}$ for 30 sec, $55^{\circ} \mathrm{C}$ for $1 \mathrm{~min}, 72^{\circ} \mathrm{C}$ for $1 \mathrm{~min}$, and then $72^{\circ} \mathrm{C}$ for $4 \mathrm{~min}$

For 2ry PCR, the cycling conditions were as follows: Heating of mixture at $93^{\circ} \mathrm{C}$ for three minutes then 30 cycles of denaturation at $93{ }^{\circ} \mathrm{C}$ for $30 \mathrm{~s}$, annealing at $58{ }^{\circ} \mathrm{C}$ for $45 \mathrm{~s}$, and extension at $72{ }^{\circ} \mathrm{C}$ for $45 \mathrm{~s}$. The expected amplification product size was $205 \mathrm{bp}$ (P.falciparum)

419 bp(P.vivax) 423 bp (P.malariae) and $410 \mathrm{bp}$ (P.ovale).

iii. Detection of PCR amplification products using gel electrophoresis and ultra-violet light (U.V) transillumination:

DNA amplification was confirmed by running PCR products on $2 \%$ agarose gel electrophoresis then stained by ethidium bromide and visualized by UV transilluminator.

Cycle sequencing and data analysis. The Plasmodium species that were detected within DNA isolates were assessed by DNA sequencing using the positive amplified PCR products and multiple alignments of obtained nucleotide sequences. Positive PCR products were prepared as follows to be sent for sequencing.

Purification of the amplified nPCR products. This procedure is done to remove unwanted impurities and contaminants as enzymes, dyes, salts, and incorporated nucleotides. Cycle sequencing. Frederick Sanger enzymatic dideoxy DNA sequencing technique is a DNA sequencing method that depends on the selection of chain-terminating dideoxynucleotide incorporation with DNA polymerase during DNA replication in vitro ${ }^{15}$. Direct 
bidirectional DNA sequencing of each purified positive nPCR product was performed.

Data Statistical analysis: Data were fed to the computer and analyzed by IBM SPSS software package version 20.0 (Armonk, NY: IBM Corp).

Quantitative data descriptions were performed using mean value. Qualitative data descriptions were performed using numbers and percentages.

P-value $>0.05$ was considered insignificant.

Ethical considerations: The study was approved by the ethical committee of Al-Azhar University, Egypt.

\section{RESULTS}

Among the examined persons, $250(33.3 \%)$ of them were females and $500(66.6 \%)$ were males. The average age was 34.6 years, ranging from 1 and 69 years. The average period between returning from the malaria-endemic area to the onset of symptoms was 14.5 days. Fever was reported in 350 cases during sampling and 400 cases had no fever during sampling. Plasmodium species were identified microscopically in 27 (3.6\%) out of 750 individuals, 13 of them were diagnosed as P. falciparum, 7 were $P$. vivax, one was $P$. ovale and 6 were mixed infection with $P$. falciparum and $P$. vivax (Table1).

\begin{tabular}{|c|c|c|}
\hline Microscopy & No. & $\%$ \\
\hline P. falciparum & 13 & 48.2 \\
\hline P. vivax & 7 & 25.9 \\
\hline P. falciparum \& $\boldsymbol{P}$. vivax & 6 & 22.2 \\
\hline P. ovale & 1 & 3.7 \\
\hline Total & 27 & 100 \\
\hline
\end{tabular}

Table (1): Distribution of positive cases by microscopy $(n=27)$

RDT was performed for the examined cases and positive results were obtained among 28 cases, twenty-seven of them had parasitemia and antigenemia while one had antigenemia only with a history of past infection.

Nested PCR for species identification was performed for 21 cases positive by first step PCR, 12 cases were $P$. falciparum, 5 cases were $P$. vivax and 4 were mixed $P$. falciparum and $P$. vivax infections (Table 2).

\begin{tabular}{|l|c|c|}
\hline nPCR & No. & $\%$ \\
\hline P.falciparum & & \\
\hline P.vivax & 12 & 57.1 \\
\hline P.falciparum \& P.vivax & 5 & 23.8 \\
\hline Total & 21 & 19.1 \\
\hline
\end{tabular}

Table (2): Distribution of positive malaria cases according to $\mathrm{nPCR}(\mathrm{n}=21)$

The result of nPCR was identical to the microscopic result (Table 3).

\begin{tabular}{|c|c|c|c|c|c|c|c|}
\hline \multirow[b]{3}{*}{ 己 } & & \multicolumn{6}{|c|}{ Microscopy } \\
\hline & & \multicolumn{2}{|c|}{$\begin{array}{c}P . \text { falciparum } \\
(\mathbf{n}=12)\end{array}$} & \multicolumn{2}{|c|}{$\begin{array}{c}P . \text { vivax } \\
(\mathrm{n}=5)\end{array}$} & \multicolumn{2}{|c|}{$\begin{array}{c}P . \text { falciparum } \\
\text { vivax } \\
(\mathrm{n}=4)\end{array}$} \\
\hline & & No. & $\%$ & No. & $\%$ & No. & $\%$ \\
\hline \multirow{3}{*}{ 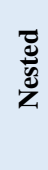 } & P.falciparum & 12 & 100.0 & 0 & 0.0 & 0 & 0.0 \\
\hline & $P$. vivax & 0 & 0.0 & 5 & 100.0 & 0 & 0.0 \\
\hline & $P$. falciparum $+P$. vivax & 0 & 0.0 & 0 & 0.0 & 4 & 100.0 \\
\hline
\end{tabular}

Table (3): Relation between microscopy and nPCR $(n=21)$

The LAST results of the sequencing of nPCR products revealed 2 species $P$. falciparum (12 cases) and $P$. vivax (5 cases). While $4 \mathrm{nPCR}$ products were positive for mixed infection of $P$. vivax and $P$. falciparum.

Past history of malaria among positive cases $(\mathrm{n}=27)$ was present in 3 cases. The major species of imported malaria were $P$. falciparum and $P$. vivax that coming from 11 African countries (Table 4). 


\begin{tabular}{|c|c|c|c|c|c|c|c|c|c|c|c|c|c|c|}
\hline & \multicolumn{12}{|c|}{ Nationality } & \multirow{2}{*}{\multicolumn{2}{|c|}{ Total }} \\
\hline & \multicolumn{2}{|c|}{ Egyptian } & \multicolumn{2}{|c|}{ American } & \multicolumn{2}{|c|}{ Chad } & \multicolumn{2}{|c|}{ Eritrean } & \multicolumn{2}{|c|}{ Nigeria } & \multicolumn{2}{|c|}{ Sudan } & & \\
\hline & No. & $\%$ & No. & $\%$ & No. & $\%$ & No. & $\%$ & No. & $\%$ & No. & $\%$ & No. & $\%$ \\
\hline \multicolumn{15}{|l|}{ Travel to } \\
\hline Guinea & 1 & 3.7 & 0 & 0.0 & 0 & 0.0 & 0 & 0.0 & 0 & 0.0 & 0 & 0.0 & 1 & 3.7 \\
\hline Angola & 1 & 3.7 & 0 & 0.0 & 0 & 0.0 & 0 & 0.0 & 0 & 0.0 & 0 & 0.0 & 1 & 3.7 \\
\hline $\begin{array}{c}\text { Camer } \\
\text { on }\end{array}$ & 1 & 3.7 & 0 & 0.0 & 0 & 0.0 & 0 & 0.0 & 0 & 0.0 & 0 & 0.0 & 1 & 3.7 \\
\hline Chad & 0 & 0.0 & 0 & 0.0 & 1 & 3.7 & 0 & 0.0 & 0 & 0.0 & 0 & 0.0 & 1 & 3.7 \\
\hline Congo & 1 & 3.7 & 0 & 0.0 & 0 & 0.0 & 0 & 0.0 & 0 & 0.0 & 0 & 0.0 & 1 & 3.7 \\
\hline Eritrea & 0 & 0.0 & 0 & 0.0 & 0 & 0.0 & 1 & 3.7 & 0 & 0.0 & 0 & 0.0 & 1 & 3.7 \\
\hline Ghana & 0 & 0.0 & 1 & 3.7 & 0 & 0.0 & 0 & 0.0 & 0 & 0.0 & 0 & 0.0 & 1 & 3.7 \\
\hline Nigeria & 3 & 11.1 & 0 & 0.0 & 0 & 0.0 & 0 & 0.0 & 1 & 3.7 & 1 & 3.7 & 5 & 18.5 \\
\hline $\begin{array}{l}\text { South } \\
\text { Africa }\end{array}$ & 2 & 7.4 & 0 & 0.0 & 0 & 0.0 & 0 & 0.0 & 0 & 0.0 & 0 & 0.0 & 2 & 7.4 \\
\hline Sudan & 9 & 33.3 & 0 & 0.0 & 0 & 0.0 & 0 & 0.0 & 0 & 0.0 & 3 & 11.1 & 12 & 44.4 \\
\hline Togo & 1 & 3.7 & 0 & 0.0 & 0 & 0.0 & 0 & 0.0 & 0 & 0.0 & 0 & 0.0 & 1 & 3.7 \\
\hline Total & 19 & 70.4 & 1 & 3.7 & 1 & 3.7 & 1 & 3.7 & 1 & 3.7 & 4 & 14.8 & 27 & 100 \\
\hline
\end{tabular}

Table (4): Distribution of positive cases according to nationality and traveling $(n=27)$

\section{DISCUSSION}

Due to a lack of awareness of clinical manifestations and methods of diagnosis of malaria among private clinics and primary health care units due to low endemicity of malaria in Egypt. Added to this, traveling of large numbers of Egyptians to malariaendemic countries for working and other different causes.

So the aim of this work was the detection of as well as genetic analysis of imported malaria in Egypt based on clinical and laboratory assessment, through the examination of 750 blood samples of suspicious malaria-infected people coming from endemic African countries using thick and thin blood film techniques, RDT for screening and Nested PCR as a confirmatory test and genetic analysis.

In the present work, it was found that out of 750 malaria suspicious patients coming from endemic countries $27(3.6 \%)$ were infected. History of fever was found in all +ve cases and this corresponding to deferent universal malaria screening research studies 16. All positive patients gave a history of travel to one of the following 11 African countries mentioned in Table 4. Most of them had a history of traveling to Sudan.

Diagnosis of Plasmodium species using microscopic examination is still the gold standard method for laboratory diagnosis $\mathbf{1 7}$. In the present work, $P$. falciparum and $P$. vivax were the two major imported malaria species. The presence of one more positive case as detected by RDT means the presence of antigenemia without parasitemia due to the particles of the parasite my still in the blood for some time after cure, so it's difficult to detect active infection from recent infection clearance. In another study, 2 cases were RDT positive but not detected microscopically due to low parasitemia or presence of malaria antigen in blood after drug intake and blood clearance of parasite $\mathbf{1 8}$

The result of nPCR was identical to the microscopic results. So results of the nPCR in our study revealed a very good confirmatory diagnostic test and with specificity and sensitivity $100 \%$ in the detection of $P$. falciparum and $P$. vivax. Another research in Thailand was performed using nPCR to detect malaria species, its result also approaches $100 \%{ }^{\mathbf{1 9}}$. A Chinese study was performed on 1420 cases to detect imported malaria. $P$. falciparum was detected in 723 cases $(50.9 \%)$ and $P$. vivax in 629 cases $(44.3 \%)$.

$P$. falciparum and $P$. vivax were the 2 major species, with $58.9 \%$ of cases coming from Africa and $39.4 \%$ coming from Southeast Asia ${ }^{20}$.

\section{CONCLUSION}

The two major malaria species in patients coming from Africa in our study were $P$. falciparum and $P$. vivax. Despite microscopic examination of Giemsa stained blood films is considered the gold standard method for laboratory diagnosis of malaria, nPCR was a very good confirmatory diagnostic test with $100 \%$ specificity and sensitivity

RDT is less specific and sensitive than nPCR, but it is rapid, simple, and lower in cost compared to $\mathrm{nPCR}$. So it can be used for screening of blood in blood bank and screening of endemic areas to detect infected cases and carriers.

\section{CONFLICT OF INTEREST}

The authors declare that they have no conflict of interest 


\section{REFERENCE}

1. World Health Organization (WHO). World Malaria Report 2013. Available at: https://www.who.int/malaria/publications/w orld_malaria_report_2013/report/en/.

Accessed 9th January 2020.

2. Gething PW, Patil AP, Smith DL, Guerra CA, and Elyazar IR et al. A new world malaria map: Plasmodium falciparum endemicity in 2010. Malar J, 2011; 10(1):378.

3. World Health Organization (WHO). World Malaria Report 2012. Available at: https://www.who.int/malaria/publications/world malaria report 2012/en/. Accessed 15th January 2020.

4. Murray CJ, Rosenfeld LC, Lim SS, Andrews $\mathrm{KG}$, and Foreman $\mathrm{KJ}$ et al. Global malaria mortality between 1980 and2010: a systematic analysis. Lancet, 2012;379(9814):413-31.

5. World Health Organization (WHO). Global malaria control and elimination - Report of a technical review. April 2008. Available at: https://www.who.int/malaria/publications/ atoz/9789241596756/en/ Accessed 19th January 2020.

6. Pluess B, Tanser FC, Lengeler C, Sharp BL. Indoor residual spraying for preventing malaria. Cochrane Database Syst Rev, 2010; 4:1-47.

7. Murray CK, Bennett JW. Rapid diagnosis of malaria. Interdiscip Perspect Infect Dis, 2009; 2009:1-7.

8. Rosenthal PJ. How do we best diagnose malaria in Africa? Am J Trop Med Hyg, 2012; 86(2):192-3.

9. Bell D, Wongsrichanalai C, Barnwell JW. Ensuring quality and access for malaria diagnosis: how can it be achieved? Nat Rev Microbiol, 2006;4(9):S7-20.

10. Imwong M, Tanomsing N, Pukrittayakamee S, Day NP and White NJ et al. Spurious amplification of a Plasmodium vivax smallsubunit RNA gene by use of primers currently used to detect P. knowlesi. J Clin Microbiol, 2009;47:4173-5.

11. Drakeley CJ, Corran PH, Coleman PG, Tongren JE, and McDonald SL et al.
Estimating medium- and long-term trends in malaria transmission by using serological markers of malaria exposure. Proc Natl Acad Sci U S A, 2005;102(14):5108-13.

12. Chotivanich K, Silamut K, Day NPJ. Laboratory diagnosis of malaria infection-a short review of methods. Aust J Med Sci, 2006; 27(1):11-5.

13. Ridley RG, White JH, McAleese SM, Goman $\mathrm{M}$, and Alano $\mathrm{P}$ et al. DNA polymerase $\delta$ : gene sequences from Plasmodium falciparum indicate that this enzyme is more highly conserved than DNA polymerase a.Nucl Acids. Res, 19(24):6731-6.

14. Li J, Wang X, Zhang G, Githure JI, and Yan $\mathrm{G}$ et al. Genome-block expression assisted association studies to discover malaria resistance genes in Anopheles gambiae. Proc Natl Acad Sci U S A, 2013; 110(51):2067580.

15. Sanger F, Coulson AR. A rapid method for determining sequences in DNA by primed synthesis with DNA Polymerase. J Mol Biol, 1975;94(3):441-8.

16. D'Acremont V, Lengeler C, Genton B. Reduction in the proportion of fevers associated with Plasmodium falciparum parasitemia in Africa: a systematic review. Malar J, 2010; 9:240.

17. Eyobo MB, Awur AC, Wani G, Julla AI, and Remijo CD et al. Malaria indicator survey 2009, South Sudan: baseline results at the household level. Malar J, 2014; 13:45.

18. Kamel MM, Attia SS, Emam GD, Al Sherbiny NA. The validity of rapid malaria tests and microscopy in detecting malaria in a pre-elimination region of Egypt. Scientifica 2016; 2016:4048032.

19. Thongdee $\mathrm{P}$, Chaijaroenkul W, Kuesap J, NaBangchang K. Nested-PCR, and a New ELISA-Based Nova Lisa Test Kit for Malaria Diagnosis in an Endemic Area of Thailand. Korean J Parasitol, 2014; 52(4):377-81.

20. Li Z, Zhang Q, Zheng C, Zhou S, and Sun J et al. Epidemiologic features of overseas imported malaria in the People's Republic of China. Malar J, 2016; 15:141. 